\title{
Occupational exposure to solvents and male infertility
}

\author{
N Cherry, F Labrèche, J Collins, T Tulandi
}

\begin{abstract}
Objectives-To determine whether, in a case-referent study of infertility patients, cases with low motile sperm count were more likely than referents to have had exposure to organic solvents.

Methods-Occupations of men attending fertility clinics in Canada were assigned codes reflecting probable exposure to organic solvents, at four grades of intensity, using a job exposure matrix previously developed. A case referent design was used, with cases being defined as men with $<12 \times 10^{6} / \mathrm{ml}$ motile sperm. Information from 656 men in manual work attending a single clinic in Montreal in 1972-91 was used for the main study. A separate analysis was conducted with information for 574 men in manual work

Main messages

- Although few workplace chemicals are shown to be reproductive toxins in humans, previous work has suggested that exposure to organic solvents might be a risk factor for male fertility.

- When this hypothesis was tested in a series of manual workers attending a single Canadian fertility clinic over a 20 year period, the odds ratio for a low active sperm count increased with intensity of exposure to solvents.

- In a further series in 10 fertility clinics across Canada, men with high exposure to solvents were again more likely to have a low active sperm count.

- Men in printing and painting occupations seemed to be at highest risk.
\end{abstract} attending 10 further clinics across Canada in 1984-7.

Results-In the Montreal series a significant association was found between intensity of exposure to solvents and clinical findings of $<12 \times 10^{6} / \mathrm{ml}$ motile sperm. Odds ratios (ORs), after allowing for confounding, were 2.07 (95\% confidence interval (95\% CI) 1.24 to 3.44$)$ for moderate exposure to solvents and 3.83 (95\% CI 1.37 to 10.65 ) for high exposure. In the second series of 568 men, the effect was confirmed at high exposure to solvents (OR 2.90, 95\% CI 1.01 to 8.34) but not at moderate exposure (OR 1.01, 95\% CI 0.53 to 1.92 ).

Conclusions-Exposure to organic solvents is common both at work and in recreational pursuits. The results of this study suggest that efforts should be made to identify the compounds hazardous to male fertility, and if the risk is confirmed, to regulate their use.

(Occup Environ Med 2001;58:635-640)

Keywords: infertility; solvents; male manual workers

Since exposure to dibromochloropropane, a nematode control agent, was shown to be associated $^{1}$ with a markedly reduced sperm count, there has been concern that other occupational exposures may affect spermatogenesis. Despite this heightened awareness, few chemicals encountered at work have been shown to be reproductive toxins in humans. ${ }^{23}$ At exposures sufficient to cause clinical lead poisoning ${ }^{4-7}$ reduced sperm concentration can be found, but evidence at lower concentrations is more equivocal. $^{89}$ Studies $^{10-12}$ from Denmark suggested that welders had an increased risk of low sperm count but the evidence is not clear. ${ }^{13} 14$
Suggestions of effects on sperm of other metals, ${ }^{15}$ pesticides, ${ }^{16}{ }^{17}$ and physical factors ${ }^{18} 19$ have come largely from single studies.

Occupational exposure to organic solvents is widespread and may have the capacity to disrupt spermatogenesis. Experimental exposure of animals can result in specific testicular damage-for example n-hexane on Sertoli cell $^{20}$ - or decrease in testicular weight with evidence of impaired spermatogenesis. ${ }^{21}{ }^{22} \mathrm{Be}-$ cause of the difficulties of conducting semen studies in industrial populations ${ }^{23}$ few systematic studies have been carried out on the effects of organic solvents on human fertility, and the epidemiological evidence is limited. An early study of carbon disulphide ${ }^{24}$ suggested marked effects on concentration, motility, and morphology, but this was not confirmed in a population with lower exposure. ${ }^{25}$ Some minor effects on sperm were found in populations exposed to perchloroethylene, ${ }^{26}$ trichloroethylene, ${ }^{27}$ styrene, ${ }^{28}$ and ethylene glycol ethers ${ }^{29-31}$ a class of organic solvents found in paints, printing, inks, and thinners (among other uses); this observation is consistent with animal studies. ${ }^{21}$

Policy implications

- Exposure to organic solvents at work is associated with damage to the nervous system (both acutely and with long term exposure) and to the skin. The present study provides further reasons for keeping exposure to a minimum.

- Further work is needed to characterise solvents most hazardous to the male reproductive system. 
Two investigations of patients attending fertility clinics provide further evidence of effects in humans exposed to solvents. In a casereferent study ${ }^{32}$ from Belgium urinary metabolites of glycol ethers were present more commonly in cases (those with abnormal semen analysis) than controls (those whose analysis seemed to be normal). A study with similar design from The Netherlands ${ }^{33}$ suggested that subjects with primary infertility were more likely to have been occupationally exposed to aromatic solvents than men attending the clinic who had normal semen variables.

The present study was begun in Canada before publication of these two European reports but with the same objective, to assess the risk of poor semen analysis associated with exposure to organic solvents at work. It began in Montreal, Quebec immediately after completion there of two large case-referent studies $^{34}{ }^{35}$ of occupational exposure to solvents and psychiatric illness. The intensity of exposure to solvents estimated from a job exposure matrix devised for these studies, when weighted by years of exposure, was related to the likelihood of organic dementia. ${ }^{34}$ Use of the matrix in a study of fertility would provide an estimate of exposure to solvents that was unbiased (except, through misclassification, towards the null) and would permit testing of a clear initial hypothesis, that exposure to organic solvents was associated with an increased risk of a poor semen analysis. Because of the much greater likelihood of exposure to solvents in manual than non-manual work, and the possibility that unmeasured, and largely unidentified, factors associated with fertility might differ with socioeconomic status, ${ }^{36}$ the study was restricted to those in manual work at the time of the first appointment at the clinic.

The study was designed to assess clinically important effects of exposure to solvents rather than to identify change in sperm count which, above the low levels needed for conception, are unlikely to be of clinical relevance. The design chosen, a case-referent study, was statistically less efficient, but clinically more relevant, than an approach that used the number of active sperm as a continuous outcome variable.

\section{Methods}

POPULATION STUDIED

Records were examined for all couples attending a single fertility clinic in Montreal (Royal Victoria Hospital, McGill University) between 1972 and 1991. Cases were excluded if the period during which pregnancy was attempted was less than 12 months or if the problem was attributed, in the record, to chromosomal abnormalities, sexual dysfunction, or recurrent abortion. The occupation at first attendance at the clinic was coded ${ }^{37}$ and those in manual work (occupational order codes 612-619, 771-991) selected for study.

Information from a second study, the Canadian infertility therapy evaluation study (CITES), ${ }^{38}$ in which the occupation of each partner had been collected, was made available to test the reproducibility of associations found in the Montreal data. Information was provided by CITES on couples who first attended one of 10 clinics across Canada between April 1984 and March 1987; cases from the 11th clinic, at the Royal Victoria Hospital, were not included, and the two series are thus independent.

DEFINITION OF CASES AND REFERENTS

Information on sperm concentration, motility, and morphology of the first semen sample was extracted from hospital records for the Montreal study and from computerised research files for CITES. The proportion of sperm with abnormal morphology proved very variable both over time in the Montreal data and between centres in the CITES series. Cases were therefore defined only by concentration and motility, which had been assessed with the methods recommended by the World Health Organisation (WHO $)^{39}$; subjects had been instructed to abstain for a period of 3 days before giving a sample. The WHO guidelines ${ }^{39}$ in use at the time put the lower bound of normal limits as a count of $20 \times 10^{6} / \mathrm{ml}$ and motility of $60 \%$. Cases, defined by the product of these, were taken as men with less than $12 \times 10^{6} / \mathrm{ml}$ active sperm. All men with a count of motile sperm of $12 \times 10^{6} / \mathrm{ml}$ or more were used as referents.

\section{MEASURES OF EXPOSURE}

The job exposure matrix constructed for the previous studies of exposure to solvents ${ }^{34} 35$ classified each job title to one of four levels of intensity of exposure to organic solvents, using exposures likely to be encountered in 1988 when the matrix was devised. Each of 13000 jobs reported in these earlier studies had been scrutinised by one of us (FL), blind to case status. For each job it was decided whether or not any exposure to solvents was possible. This assessment was then tabulated against three figure job codes, and all categories with more than 10 jobs in which at least one was assessed as having possible exposure to solvents were retained. The occupational titles and job descriptions provided by Statistics Canada $^{37}$ were assessed separately by three international experts. They were asked to rate the job on a four point scale in which (a) "no" exposure implied no more than background levels, (b) "some" less than $30 \%$ of the threshold limit values (TLV), (c) "moderate" $30 \%-50 \%$, and (d) "high" greater than $50 \%$. The median rating of the three assessors was taken as the estimate of exposure in all jobs with that three figure code. Overall, 35 job titles were classified at level 1, 11 at level 2, and only five (painters in construction, printing press operators, other printing operatives, launderers and dry cleaners, workers in marine craft fabrication) at level 3. The code of the job title recorded at the first appointment was matched to this matrix and the level of intensity of exposure to solvents assigned.

Occupation titles were coded for the Montreal series blind to case status, by a clerical worker trained by Statistics Canada and by our team for the CITES series. Only one important 
discrepancy was apparent, with "mechanics" being assigned to different categories by the trained and untrained coders. To ensure comparability between the series, mechanics were assigned an exposure to solvents rating of 2 (moderate) consistent with the exposure rating of the occupational code used most often by the trained coder.

POTENTIAL CONFOUNDERS

Three potential confounders were considered; age, year of first appointment at the clinic, and occupational exposure to lead. In the CITES study all patients were first seen during a short period (1984-7) and the date was not available. An indicator of possible exposure to lead was derived from the previous Quebec casereferent studies. ${ }^{345}$ Jobs recorded on at least 10 occasions in which $10 \%$ or more had reported lead exposure were taken as a marker of possible exposure that could be applied to both the Montreal and the CITES series. Each job title was thus coded as entailing possible exposure to solvents (graded 0-3) and lead (present or absent).

In the Montreal series information on alcohol and tobacco smoking was extracted where available and coded to indicate whether the patient had ever smoked or ever drunk alcohol regularly.

\section{MARKERS OF FERTILITY}

A history of previous pregnancies, with any partner, was collected at the first clinic visit in the Montreal series. From the data requested from the CITES series, only previous pregnancies with the same partner could be extracted. The presence of tubal occlusion, ovulatory problems, other abnormalities, or no defect in the female partner was extracted from the Montreal clinic records. The clinical data from the CITES series provided closely similar definitions of abnormalities.

\section{STATISTICAL ANALYSIS}

The data were analysed using a case-referent design with logistic regression analysis to assess the risk associated with exposure to solvents, both unadjusted and with adjustment for potential confounders. A third step included markers of fertility; such markers would be highly related to case status and adjustment for chance variation would increase the precision of the other risk estimates. Analysis at each step was carried out for the two series separately, with the CITES series serving to test the consistency of the relations found in the Montreal data.

\section{Results}

In the Montreal series 2315 (91.0\%) of 2544 men were in paid work and of these 796 were in manual jobs, 1325 in non-manual work, and 194 in jobs that could not be classified. Of those in manual jobs $656(82.4 \%)$ had an initial semen analysis for which both count and motility had been recorded. In the CITES series $93.1 \%$ were in work $(1563 / 1679)$. Of these 647 were in manual jobs, 875 in non-manual, and 41 in jobs not classified. Concentration and motility were recorded at the first semen analysis for $574(88.7 \%)$. The proportions with low active sperm $\left(<12 \times 10^{6}\right)$ were very similar in manual workers in the two series (31.8\%, Montreal; 30.5\%, CITES).

The distribution of cases and referents by potential confounders and markers of fertility is shown in table 1. Men in the Montreal series were older (mean age 32.1 years) than in the CITES series (30.6 years) and were less likely to be in jobs with possible exposure to lead. More men in Montreal (24.7\%) than in the CITES series (18.8\%) reported a previous pregnancy. The proportion with a partner in whom no abnormality had been found was similar in the two series (Montreal 39.9\%, CITES 39.8\%). The differences between cases and referents within series were small for potential confounders but highly significant for both markers of fertility in each of the series.

In the Montreal series information on smoking and alcohol was recorded for similar proportions of cases and referents (smoking $82.1 \%$ cases, $81.0 \%$ referents; alcohol $74.8 \%$ cases, $74.0 \%$ referents). For those with data, little difference was found (cases ever smoked $65.9 \%$, referents $64.5 \%$; cases who drank alcohol $75.2 \%$, referents $73.2 \%$ ).

Exposure to solvents was greater in cases than referents in Montreal (table 2) with

Table 1 Characteristics of cases (active sperm $<12 \times 10^{6} / \mathrm{ml}$ ) and referents (active sperm $\geqslant 12 \times 10^{6} / \mathrm{ml}$ ) in the Montreal and CITES series

\begin{tabular}{|c|c|c|c|c|c|c|c|c|}
\hline & \multicolumn{4}{|c|}{ Montreal } & \multicolumn{4}{|c|}{ CITES } \\
\hline & \multicolumn{2}{|l|}{ Cases } & \multicolumn{2}{|c|}{ Referents } & \multicolumn{2}{|l|}{ Cases } & Referents & $\%$ \\
\hline \multicolumn{9}{|l|}{ Age $(y)$ : } \\
\hline$\leqslant 30$ & 78 & 37.5 & 189 & 42.4 & 90 & 52.3 & 202 & 51.0 \\
\hline $31-35$ & 74 & 35.6 & 124 & 27.8 & 58 & 33.7 & 130 & 32.8 \\
\hline$>35$ & 56 & 26.9 & 133 & 29.8 & 24 & 14.0 & 64 & 16.2 \\
\hline All & 208 & 100.0 & 446 & 100.0 & 172 & 100.0 & 396 & 100.0 \\
\hline \multicolumn{9}{|l|}{ Clinic year: } \\
\hline $1972-76$ & 76 & 36.2 & 168 & 37.7 & - & - & - & - \\
\hline $1977-81$ & 65 & 31.0 & 139 & 31.2 & - & - & - & - \\
\hline $1982-91$ & 69 & 32.9 & 139 & 31.2 & 175 & 100.0 & 399 & 100.0 \\
\hline All & 210 & 100.0 & 446 & 100.0 & 175 & 100.0 & 399 & 100.0 \\
\hline Possible lead exposure & 37 & 17.6 & 81 & 18.2 & 44 & 25.1 & 114 & 28.6 \\
\hline No previous pregnancy & 176 & 84.2 & 316 & $71.2^{\star \star \star}$ & 155 & 88.6 & 311 & $77.9^{\star \star}$ \\
\hline Partner 'normal' & 100 & 47.6 & 162 & $36.3^{\star \star}$ & 105 & 60.0 & 124 & $31.1^{\star \star \star}$ \\
\hline
\end{tabular}

${ }^{\star}$ Information missing for 1 case and 2 referents in the Montreal study.

$\star \star \mathrm{p}<0.01$ cases $v$ referents.

$\star \star \star \mathrm{p}<0.001$ cases $v$ referents. 
Table 2 Solvent exposure in cases and referents*

\begin{tabular}{|c|c|c|c|c|c|}
\hline & & \multicolumn{2}{|c|}{ Montreal } & \multicolumn{2}{|c|}{ CITES } \\
\hline \multicolumn{2}{|c|}{ Solvent exposure } & Cases & Referents & Cases & Referents \\
\hline None & $\begin{array}{l}\mathrm{n} \\
\%\end{array}$ & $\begin{array}{c}123 \\
58.2\end{array}$ & $\begin{array}{l}300 \\
67.3\end{array}$ & $\begin{array}{l}115 \\
65.7\end{array}$ & $\begin{array}{c}264 \\
66.2\end{array}$ \\
\hline Low & $\begin{array}{l}\mathrm{n} \\
\%\end{array}$ & $\begin{array}{l}39 \\
18.8\end{array}$ & $\begin{array}{l}84 \\
18.2\end{array}$ & $\begin{array}{l}30 \\
17.1\end{array}$ & $\begin{array}{l}72 \\
18.1\end{array}$ \\
\hline Moderate & $\begin{array}{l}\mathrm{n} \\
\%\end{array}$ & $\begin{array}{l}38 \\
18.3\end{array}$ & $\begin{array}{l}54 \\
12.1\end{array}$ & $\begin{array}{l}22 \\
12.6\end{array}$ & $\begin{array}{l}56 \\
14.0\end{array}$ \\
\hline High & $\begin{array}{l}\mathrm{n} \\
\%\end{array}$ & $\begin{array}{c}10 \\
4.8\end{array}$ & $\begin{array}{l}8 \\
1.8\end{array}$ & $\begin{array}{l}8 \\
4.6\end{array}$ & $\begin{array}{l}7 \\
1.8\end{array}$ \\
\hline All & $\begin{array}{l}\mathrm{n} \\
\%\end{array}$ & $\begin{array}{l}210 \\
100.0\end{array}$ & $\begin{array}{l}446 \\
100.0\end{array}$ & $\begin{array}{l}175 \\
100.0\end{array}$ & $\begin{array}{l}399 \\
100.0\end{array}$ \\
\hline
\end{tabular}

${ }^{\star}$ Cases $=$ active sperm $<12 \times 10^{6} / \mathrm{ml} ;$ referents=active sperm $\geqslant 12 \times 10^{6} / \mathrm{ml}$

$23.1 \%$ of cases but only $13.9 \%$ of referents in occupations with potential exposure to moderate or high concentrations of solvents. In the CITES series, this excess was found only with high exposure. The median sperm count decreased with increasing exposure to solvents in the Montreal series (none $29 \times 10^{6}$, some $28 \times 10^{6}$, moderate $21 \times 10^{6}$, high $10 \times 10^{6}$ ) and with high exposure in the CITES series (none $28 \times 10^{6}$, some $29 \times 10^{6}$, moderate $33 \times 10^{6}$, high $\left.7 \times 10^{6}\right)$.

The risk of low active sperm count associated with exposure to solvents was estimated from odds ratios (ORs) calculated by logistic regression (table 3 ). The unadjusted estimates from the Montreal study showed an increased risk at both moderate (OR 1.72) and high (OR 3.05) exposures. Adjustment for confounders increased the estimate of risk (to 2.07, moderate; 3.83 , high) with a small further increase after adjustment for fertility markers. In the CITES data, only high (and not moderate) exposure resulted in increased risk, significant after adjustment for confounders (OR 2.90). When markers of fertility were included in the equation the estimate of risk with high exposure was very similar (3.82) to that for high exposure to solvents (3.88) in the Montreal study. Inclusion of data (where available) on smoking and alcohol in the Montreal analysis served to increase, rather than reduce, the size of the estimate of risk associated with exposure to solvents (data not shown).

In the two series only 33 men $(2.7 \%)$ were in the five jobs rated initially as involving high exposure to solvents. Among these men were

Table 3 Exposure to solvents and risk of low active sperm $\left(<12 \times 10^{6} / \mathrm{ml}\right)$ (logistic regression analysis)

\begin{tabular}{|c|c|c|c|}
\hline & $\begin{array}{l}\text { Unadjusted } \\
\text { OR }(95 \% \text { CI) }\end{array}$ & $\begin{array}{l}\text { Adjusted for } \\
\text { confounders } \\
\text { OR }(95 \% \text { CI) }\end{array}$ & $\begin{array}{l}\text { Adjusted for confounders } \\
\text { and fertility markerst } \\
\text { OR }(95 \% \text { CI })\end{array}$ \\
\hline \multicolumn{4}{|l|}{ Montreal: } \\
\hline \multicolumn{4}{|c|}{ Exposure to solvents ( $v$ none): } \\
\hline Low & $1.13(0.73$ to 1.75$)$ & $1.21(0.78$ to 1.89$)$ & $1.23(0.78$ to 1.92$)$ \\
\hline Moderate & $1.72(1.08$ to 2.73$)$ & $2.07(1.24$ to 3.44$)$ & $2.17(1.29$ to 3.66$)$ \\
\hline High & $3.05(1.18$ to 7.91$)$ & $3.83(1.37$ to 10.65$)$ & $3.88(1.37$ to 11.02$)$ \\
\hline \multicolumn{4}{|l|}{ CITES: } \\
\hline \multicolumn{4}{|c|}{ Exposure to solvents ( $v$ none): } \\
\hline Low & $0.96(0.59$ to 1.54$)$ & $0.98(0.61$ to 1.61$)$ & $1.07(0.65$ to 1.79$)$ \\
\hline Moderate & $0.90(0.53$ to 1.55$)$ & $1.01(0.53$ to 1.92$)$ & $1.03(0.53$ to 2.03$)$ \\
\hline High & $2.63(0.93$ to 7.41$)$ & $2.90(1.01$ to 8.34$)$ & $3.82(1.25$ to 11.69$)$ \\
\hline
\end{tabular}

*Possible exposure to lead, age, and (Montreal only) date of clinic attendance.

$\dagger$ No record of previous pregnancy, no female abnormality found. nine printing press operators, of whom six were cases $(66.7 \%)$, five other printers with three cases $(60 \%), 12$ painters and decorators with six cases $(50 \%)$, two laundry and dry cleaning workers with one case $(50 \%)$, and five shipbuilding and repair workers with two cases $(40 \%)$. Overall the proportion of cases was $54.6 \%$ in high exposure jobs $(55.6 \%$ in Montreal, $53.3 \%$ in CITES).

\section{Discussion}

The Montreal study was set up to test a specific, biologically plausible, hypothesis that exposure to organic solvents at work was associated with a clinically important reduction in count of motile sperm. This hypothesis was supported, with a clear increase in risk at higher intensity of exposure. Data from the CITES series, used as an independent validation, confirmed an increased risk at high concentrations.

These findings are consistent with those of two recent European studies, ${ }^{32}{ }^{33}$ but the possibilities of bias and confounding must be considered. Definition of referents from within the clinic population reduced the risk of bias arising from differential referral patterns. Bias in the reporting and assessment of exposure was minimised by use of a previously developed matrix depending only on the job title recorded before investigation and diagnosis. Misclassification both of case status (based on a routine analysis of a single semen sample) and of exposure level will certainly have occurred, but will tend to reduce rather than increase the estimate of risk. ${ }^{40}$

Confounding is considered, in part, by limiting the analysis to those in manual work. Within this group the potential confounders of tobacco and alcohol were unrelated (in the Montreal series) to case status. The possibility that exposure to organic solvents is simply a marker for some other occupational exposure that is itself harmful to the male reproductive system must also be considered. Most subjects assessed as highly exposed to solvents were printers or construction painters and, as such, were potentially exposed to lead; in the present study adjustment for lead, based solely on job title, will be imperfect but nevertheless suggests that this exposure is not sufficient to explain the consistently greater proportion of cases in those jobs assessed as highly exposed to solvents. No other exposure, apart from organic solvents, seems common to these occupations.

Patients in the Montreal series were seen during a 20 year period and this, in itself, introduces a further possibility of confounding. It is likely that both the type and intensity of exposure to solvents will have changed over time. The assessment of exposure for the present study was based on likely exposures to solvents at the time of developing the matrix and as such may underestimate exposures in those attending the clinic in the early years. The proportion of patients in jobs rated as having high exposure to solvents was greater in 1982-91 (12 of 280 patients; $5.8 \%$ ) than in $1972-81$ (six of 448 patients; $1.3 \%$ ) but within this high exposure group the proportion of 
cases was similar $(6 / 12,4 / 6)$. There was little suggestion (table 1 ) that the proportion with low motile sperm was greater overall in more recent years (as might be expected if sperm counts were decreasing ${ }^{41}$ ) but this absence of a trend is difficult to interpret given changes in lifestyle, referrals, and assessment procedures during these years. Analysis of changes in sperm count in the 11 clinics included in the present paper showed no decline for the period 1975-96 but a small overall decline when just the period 1984-96 was examined. ${ }^{42}$

The finding that exposure to solvents is associated with low motile sperm count in clinically infertile couples is important both because of the widespread use of solvents and the possibility of prevention through the reduction of exposures at work (assuming that some, at least, of the infertile men might have been fertile in the absence of exposure). Although it must be noted that only $2.7 \%$ of the manual workers were in occupations judged as entailing high exposure to solvents, many men with high exposures will be found outside this narrow range of work. Veulemans et $a l^{22}$ found metabolites of glycol ethers in $3.2 \%$ of all men (not simply manual workers) investigated for infertility at one clinic, and moderate or high exposure to solvents, assessed by questionnaire, was recorded for some $12 \%$ of all men attending two fertility clinics in The Netherlands. ${ }^{33}$ In the present study the twofold increase in risk in the $14 \%$ of men exposed to moderate levels of exposure to solvents in Montreal was not confirmed in the CITES series, but given the bluntness of the measure of exposure and the biological plausibility of the dose-response pattern found in the Montreal data, effects at moderate or lower levels of exposure cannot be discounted.

Control of a hazard can be approached more rationally if it is clearly identified; at present it is not known whether all solvents carry a risk at high concentrations or whether there are exposures common to many solvent mixtures that would explain the relation found. A prime candidate would be the glycol ethers, known reproductive toxins in animals. ${ }^{21}$ Metabolites were shown to be associated with poor semen analysis in a clinic based case-referent study ${ }^{32}$; although this is suggestive of a direct effect of glycol ethers, the men with such metabolites were in jobs (printing, painting) that also involved exposures to solvents found more generally. The authors of the recent study ${ }^{33}$ from The Netherlands interpreted their own results as implicating particularly the aromatic solvents - such as toluene and xylene-but they thought it unlikely, in view of the small proportion with measurable metabolites of glycol ethers, that these were a sufficient cause for the increased risk of poor semen analysis in patients exposed to solvents.

The present study cannot throw further light on the exact nature of the toxic exposure of those in jobs characterised by use of solvents nor can it adequately measure the risk. It does, however, add considerably to the body of data suggesting that organic exposure to solvents constitutes a hazard for male fertility.
This study was supported by a grant to McGill University by the National Health Research and Development Program of Health and Welfare, Canada.

1 Whorton D, Krauss RM, Marshall S, et al. Infertility in male pesticide workers. Lancet 1977;ii:1259-61.

2 Tas S, Lauwerys R, Lison D. Occupational hazards for the male reproductive system. Crit Rev Toxicol 1996;26:261male

3 Cherry NM. Occupations and infertility. In: McDonald JC, ed. Epidemiology of work related diseases, 2 nd ed. London: BMJ Books, 2000:361-80.

4 Lancranjan I, Popescu HI, Gavanescu O, et al. Reproductive ability of workmen occupationally exposed to lead. Arch Environ Health 1975;30:396-401.

5 Cullen MR, Kayne RD, Robins JM. Endocrine and reproductive dysfunction in men associated with occupational inorganic lead intoxication. Arch Environ Health 1984;39:431-40.

6 Lerda D. Study of sperm characteristics in persons occupationally exposed to lead. Am F Ind Med 1992;22:567-71.

7 Assennato G, Paci C, Molinini R, et al. Sperm count suppression without endocrine dysfunction in leadexposed men. Arch Environ Health 1987;42:124-7.

8 Alexander BH, Checkoway H, van Netten C, et al. Semen quality of men employed at a lead smelter. Occup Environ Med 1996;53:411-16.

9 Robins TG, Bornman MS, Ehrlich R, et al. Semen quality and fertility of men employed in a South African lead acid battery plant. Am f Ind Med 1997;32:369-76.

10 Mortensen JT. Risk for reduced sperm quality among metal workers, with special reference to welders. Scand $\mathcal{F}$ Work Environ Health 1988;14:27-30.

11 Bonde JP. Semen quality and sex hormones among mild steel and stainless steel welders: a cross sectional study. $\mathrm{Br}$ F Ind Med 1990;47:508-14.

12 Bonde JP. Subfertility in relation to welding. A case-referent study among male welders. Dan Med Bull 1990;37:105

13 Hjollund NHI, Bonde JPE, Jensen TK, et al. A follow up study of male exposure to welding and time to pregnancy. Reprod Toxicol 1998;12:29-37.

14 Hjollund NHI, Bonde JPE, Jensen TK, et al. Semen quality and sex hormones with reference to metal welding. Reprod Toxicol 1998;12:91-5.

15 Lauwerys R, Roels H, Genet P, et al. Fertility of male workers exposed to mercury vapour or to manganese dust: a questionnaire study. Am f Ind Med 1985;7:171-6.

16 Ratcliffe JM, Schrader SM, Steenland K, et al. Semen quality in papaya workers with long term exposure to ethylene dibromide. Br f Ind Med 1987;44:317-26.

17 Whorton MD, Milby TH, Stubbs HA. Testicular function among carbaryl-exposed employees. F Toxicol Environ Health 1979;5:929-41.

18 Figà-Talamanca I, Dell'Orco V, Pupi A, et al. Fertility and semen quality of workers exposed to high temperatures in the ceramics industry. Reprod Toxicol 1992;6:517-23.

19 Figà-Talamanca I, Cini C, Varricchio GC, et al. Effects of prolonged autovehicle driving on male reproductive function: a study among taxi drivers. Am F Ind Med 1996; 30:750-8.

20 Boekelheide $\mathrm{K}$. Rat testis during 2,5-hexanedione intoxication and recovery. Toxicol Appl Pharmacol 1988;92:18-27.

21 Hardin BD. Reproductive toxicity of the glycol ethers. Toxicology 1983;27:91-102

22 Yamada K. Influence of lacquer thinner and some organic solvents on reproductive and accessory reproductive organs in the male rat. Biol Pharm Bull 1993;16:425-7.

23 Bonde JP, Giwercman A, Ernst E. Identifying environmental risk to male reproductive function by occupational sperm studies: logistics and design options. Occup Environ sperm studies: logistics
Med 1996;53:511-19.

24 Lancranjan I, Popescu HI, Klepsch I. Changes of the gonadic function in chronic carbon disulfide poisoning. Med Lavoro 1969;60:566-73.

25 Meyer CR. Semen quality in workers exposed to carbon disulfide compared to a control group from the same plant. 7 Occup Med 1981;23:435-9.

26 Eskenazi B, Wyrobek AJ, Fenster L, et al. A study of the effect of perchloroethylene exposure on semen quality in
dry cleaning workers. Am f Ind Med 1991;20:575-91.

27 Chia SE, Ong CN, Tsakok MFH, et al. Semen parameters in workers exposed to trichloroethylene. Reprod Toxicol 1996;10:295-9.

28 Kolstad HA, Bonde JP, Spano M, et al. Change in semen quality and sperm chromatin structure following occupaional styrene exposure. ASCLEPIOS. Int Arch Occup Environ Health 1999;82:135-41.

29 Cook RR, Bodner KM, Kolesar RC, et al. A cross-sectional study of ethylene glycol monomethyl ether process employees. Arch Environ Health 1982;37:346-51.

30 Welch LS, Schrader SM, Turner TW, et al. Effects of exposure to ethylene glycol ethers on shipyard painters: II Male reproduction. Am F Ind Med 1988;14:509-26.

31 Ratcliffe JM, Schrader SM, Clapp DE, et al. Semen quality in workers exposed to 2-ethoxyethanol. BrF Ind Med 1989; 46:399-406

32 Veulemans H, Steeno O, Masschelein R, et al. Exposure to ethylene glycol ethers and spermatogenic disorders in man: a case-control study. Br f Ind Med 1993;50:71-8.

33 Tielemans E, Burdorf A, te Velde ER, et al. Occupational related exposures and reduced semen quality: a casecontrol study. Fertil Steril 1999;71:690-6. 
34 Cherry NM, Labrèche FP, McDonald JC. Organic brain damage and occupational solvent exposure. Br f Ind Med damage and occupa

35 Labrèche FP, Cherry NM, McDonald JC. Psychiatric disorders and occupational exposure to solvents. $\mathrm{Br} \mathcal{F}$ Ind Med 1992;49:820-5

36 Howe G, Westhoff C, Vessey M, et al. Effects of age, cigarette smoking, and other factors on fertility: findings of a large prospective study. BMF 1985;290:1697-700.

37 Statistics Canada. Occupational coding manual. Census of Canada. Ottawa 1986. (Publ No R-423.)

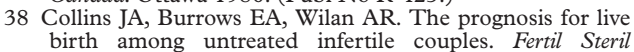
1995;64:22-8.
39 World Health Organization. Laboratory manual for the examination of human semen and semen-cervical mucus interaction, 1st ed. Singapore: Press Concern, 1980.

40 Armstrong BK, White E, Saracci R. Principles of exposure measurement in epidemiology. New York: Oxford University Press, 1992.

41 Irvine S, Cawood E, Richardson D, et al. Evidence of deteriorating semen quality in the United Kingdom: birth cohort study in 577 men in Scotland over 11 years. BMF 1996;312:467-71.

42 Younglai EV, Collins JA, Foster WG. Canadian semen quality: an analysis of sperm density among eleven academic fertility centers. Fertil Steril 1998;70:76-80.

\section{Open reviewing}

Many journals, including the BMJ, have moved to a system of open reviewing, whereby authors know the names of reviewers of their papers. Research has shown that named reviews, although not of better quality than anonymous reviews, are not of worse quality either. Therefore in the interests of transparency, it seems fair to let authors know who has reviewed their paper. At Occupational and Environmental Medicine we have considered the issue carefully. There are some concerns that reviewers, especially those who are more junior, might feel intimidated and not wish to make negative comments about papers submitted by senior people in the field. On the other hand, some reviewers might hide behind the cloak of anonymity to make unfair criticisms so as to reduce the chances of publication by rivals. We have decided to introduce initially a system of open reviewing if the reviewers agree explicitly. So when a reviewer is sent a paper, he or she is asked to indicate whether we can disclose their name or not when sending the authors their comments. We will be monitoring this to see how many of our reviewers are happy to be named. If it is most of them, we will move to a system of open reviewing as the norm, with a possible "opt out" clause for reviewers. 